TecnoLógicas

ISSN-p 0123-7799

ISSN-e 2256-5337

Vol. 21, No. 42 , pp. $63-78$

Mayo-agosto de 2018

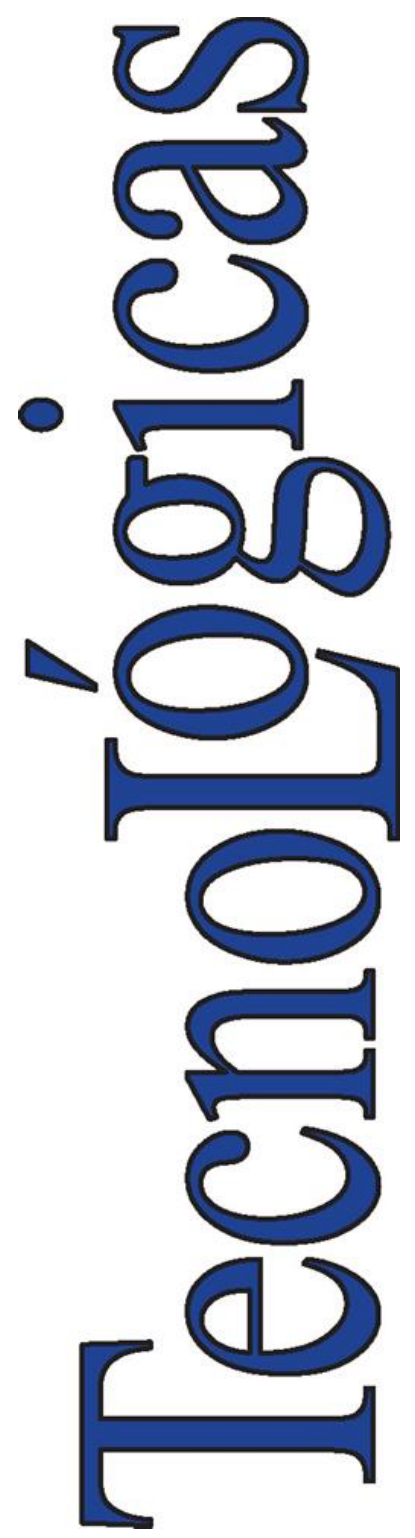

(C) Copyright 2015 por autores y Tecno Lógicas Este trabajo está licenciado bajo una Licencia Internacional Creative Commons Atribución (CC BY)

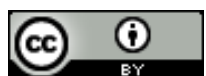

\section{Secondary voltage regulation based on average voltage control}

\section{Regulación secundaria de voltaje basada en el control del voltaje promedio}

\author{
Edwin H. Lopera-Mazo ${ }^{1}$, \\ y Jairo Espinosa ${ }^{2}$
}

Recibido: 05 de febrero de 2018

Aceptado: 20 de abril de 2018

Cómo citar / How to cite

E. H. Lopera-Mazo, y J. Espinosa, Secondary voltage regulation based on average voltage control. TecnoLógicas, vol. 21, no. 42, pp. 63-78, 2018.

MSc. in Engineering, Electrical Engineer, Facultad de Minas, Universidad Nacional de Colombia, Facultad de Ingenierías, Instituto Tecnológico Metropolitano, Medellín-Colombia, eloperam@unal.edu.co

2 PhD. in Applied Sciences, MSc. in Engineering, Electronic Engineer, Facultad de Minas, Universidad Nacional de Colombia, Medellín-Colombia, jespinov@unal.edu.co 


\section{Abstract}

This paper compares a conventional Secondary Voltage Regulation (SVR) scheme based on pilot nodes with a proposed SVR that takes into account average voltages of control zones. Voltage control significance for the operation of power systems has promoted several strategies in order to deal with this problem. However, the Hierarchical Voltage Control System (HVCS) is the only scheme effectively implemented with some relevant applications into real power systems.

The HVCS divides the voltage control problem into three recognized stages. Among them, the SVR is responsible for managing reactive power resources to improve network voltage profile. Conventional SVR is based on dividing the system into some electrically distant zones and controlling the voltage levels of some specific nodes in the system named pilot nodes, whose voltage levels are accepted as appropriate indicators of network voltage profile.

The SVR approach proposed in this work does not only consider the voltage on pilot nodes, but it also takes the average voltages of the defined zones to carry out their respective control actions. Additionally, this innovative approach allows to integrate more reactive power resources into each zone according to some previously defined participation factors.

The comparison between these strategies shows that the proposed SVR achieves a better allocation of reactive power in the system than conventional SVR, and it is able to keep the desired voltage profile, which has been expressed in terms of network average voltage.

\section{Keywords}

Secondary Voltage Regulation, Average voltage, Conventional SVR, Hierarchical Voltage Control System, Power System.

\section{Resumen}

En este trabajo se realiza una comparación entre un esquema convencional de Regulación de Voltaje Secundario (RVS) que se basa en nodos piloto y un RVS propuesto, que toma en cuenta los voltajes promedio de las zonas de control. La importancia del control de voltaje para la operación de los sistemas de potencia ha promovido varias estrategias para enfrentar este problema. Sin embargo, el Sistema de Control de Voltaje Jerárquico (SCVJ) es el único esquema efectivamente implementado con algunas aplicaciones relevantes en sistemas de potencia reales.

El SCVJ divide el problema de control de voltaje en tres etapas reconocidas. Entre ellas, la RVS es la encargada de gestionar los recursos de potencia reactiva para mejorar el perfil de tensión de la red. La RVS Convencional se basa en la división del sistema en algunas zonas eléctricamente distantes y en controlar los niveles de tensión de algunos nodos específicos del sistema denominados nodos piloto, cuyos niveles de tensión se aceptan como indicadores adecuados del perfil de tensión de la red.

La RVS propuesta en este trabajo no solo considera el voltaje en los nodos piloto, sino que también toma los voltajes promedio de las zonas definidas para llevar a cabo sus respectivas acciones de control. Además, este nuevo enfoque permite integrar más recursos de potencia reactiva en cada zona de acuerdo con algunos factores de participación previamente definidos. La comparación entre estas dos estrategias muestra que la RVS propuesta logra una mejor asignación de la potencia reactiva en el sistema con respecto a la 
SVR convencional y que es capaz de mantener un perfil de voltaje deseado, el cual ha sido expresado en términos de la tensión media de la red.

\section{Palabras clave}

Regulación de Voltaje Secundario, Voltaje promedio, RVS convencional, Control de Voltaje Jerárquico, sistema eléctrico de potencia. 


\section{INTRODUCTION}

Keeping all node voltage levels within an appropriate operating range and controlling reactive power flow constitute some of the most important tasks in the operation of an electric power system [1]. Some relevant electric service aspects such as efficiency, stability, safety, reliability and energy quality directly depend on the regulation of these variables [2].

Many proposals have been studied and developed in order to improve voltage control in transmission systems. Among these alternatives, the Hierarchical Voltage Control System (HVCS) has been widely recognized as a viable solution, because it has been satisfactorily adopted in some countries [3]. HVCS has shown superior performance compared with early schemes where secondary voltage regulation particularly has been done in a manual way [4].
HVCS solves the voltage control problem by geographically and temporarily dividing the electric power system considering three hierarchical levels. This division aims to limit interference between involved control actions. These three levels are known as Primary (PVR), Secondary (SVR), and Tertiary Voltage Regulation (TVR) [5], as shown Fig. 1.

PVR is based on the operation of Automatic Voltage Regulator (AVR), which changes the magnetic field applied to the network's synchronous generators and other kinds of reactive compensation controllers, such as capacitor and reactor banks, and on-load tap changers, among other. This level only operates with local voltage measurements and presents response times of some fractions of a second for node voltage correction where this control is applied [6].

According to the theoretical foundation of conventional SVR, voltage control is

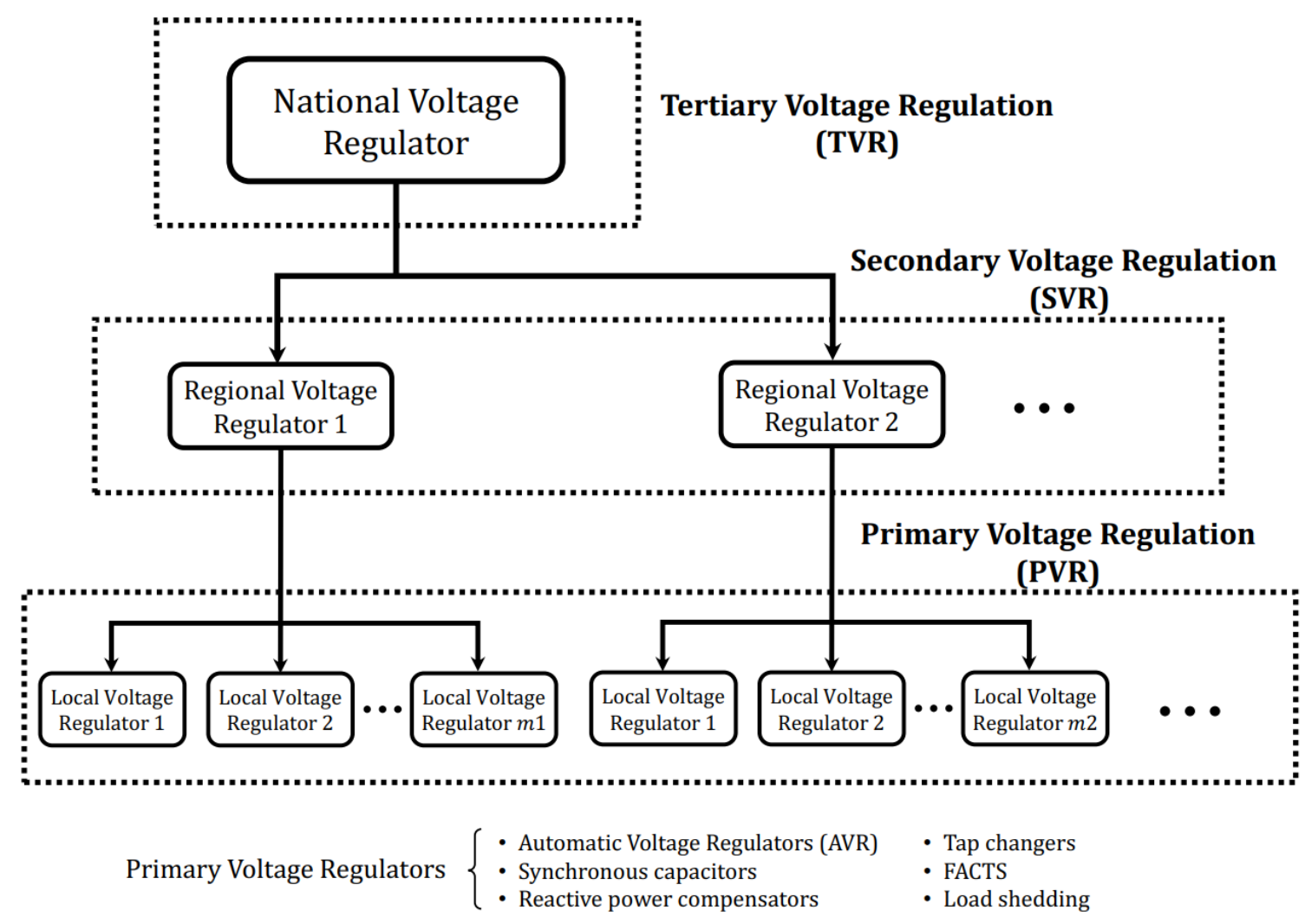

Fig. 1. Hierarchical structure of the coordinated voltage control. Source: Authors' own work. 
essentially a local problem where electrically close nodes exhibit similar voltage variation in the presence of network disturbances. Therefore, the previous step before applying conventional SVR consists in dividing the system into voltage control zones with low electrical coupling. However, many factors could affect this coupling between the defined areas; as a result, conventional SVR's performance would be significantly degraded after a particular disturbance [7].

After the definition of these zones, conventional SVR executes a coordinated control of the reactive power resources related to the PVR in each of these areas. If the PVR is based on AVR operation, conventional SVR dynamically adjusts the operation points of this equipment. The generators chosen for participating in voltage regulation in each zone are known as control generators. The main objective of these generators is to adjust voltage levels of some specific nodes from each zone, named pilot nodes [8], [9]. Finding a specific weighted partition of the reactive power provided from each zone control generator is the most-commonly used criterion in this traditional scheme. The aim is to keep a convenient reactive power margin in each control zone to face eventual voltage contingencies. SVR takes more time to respond than PVR and it exhibits time constants close to three minutes.

In a superior level of this hierarchical structure is the TVR. This stage defines reference values for pilot node voltages normally based on an optimal power flow analysis for this estimation. Typically, this stage tries to minimize system energy losses or to maximize loading according to security and economic constraints. TVR presents time constants near to ten minutes [10].

In order to define the voltage control zones and their corresponding pilot nodes several methods have been proposed [11]. This task constitutes one of the most important issues for HVCS implementation, but the principles behind system partition are basically the same [12]: 1) a strong coupling between nodes in the same zone; 2) reactive controllable resources in each zone; and 3) appropriate number of zones to implement regional control. The most commonly-used method considers short circuit level of nodes and it uses a voltage sensibility matrix derived from the system's Jacobian matrix. The analytical procedure is based on the sensibility matrix of node voltage changes regarding injected reactive power changes in each node when only PVR operates [10].

In conventional SVR, each voltage control zone is essentially characterized by its own pilot node voltage; therefore, the controllers cannot perceive significant variations in the voltage levels of electrically remote areas from this node, which can adversely affect power electric performance. This problem could be more relevant in nodes near the boundaries of two or more control zones, because these nodes should be electrically more distant from the pilot nodes of each zone.

This paper presents a method that characterizes network voltage profile through a performance indicator based on some (or perhaps all) node voltages that belong to each area, instead of using only pilot nodes. The proposed SVR includes more node voltages, even those located near bordering areas, and it provides greater flexibility because changing the participant nodes is easier. This method also conveniently controls reactive power injection in each zone in comparison with a conventional SVR scheme. Moreover, the proposed SVR offers great possibilities for progressively adapting the control scheme to topology changes that could be present in the network.

The results presented in this paper could have a relevant impact on currently implemented SVR schemes based on the pilot nodes, because this new proposal maintains voltage control zone partitioning. Additionally, although the proposed 
SVR is not based on optimization algorithms as in some recent approaches, this scheme allows to easily integrate new control strategies into the HVCS.

\section{METHOD}

\subsection{Conventional SVR}

Fig. 2 shows the conventional SVR as commonly used in a specific voltage control zone within the HVCS structure. In this scheme, AVR sets the PVR and its main task is manipulating excitation system of control generators in each area in order to reach a specific stator voltage reference. Meanwhile, SVR leads the voltage reference value of each control generator towards a new specific reference. This secondary stage has normally adopted two approaches to change AVR voltage references with longer time constants. Handling the injected reactive power in each control zone according to the changes of pilot node voltages is a first relevant feature of the conventional SVR. The other important aspect of this stage corresponds to the application of weighted participation factors for all devices injecting reactive power in each zone, in order to have an appropriate reactive power reserve in the network to support voltage contingencies. These two features encourage establishing voltage control zones with low electric coupling coefficients [13].

\subsection{Definition of voltage control zones and pilot nodes}

Several methods have been proposed for dividing an electric network into voltage control zones and defining their respective pilot nodes. The most widely-used and implemented method for this division is based on electrical distances and short circuit levels of nodes, which is derived from a stationary analysis of the system's variables [11].

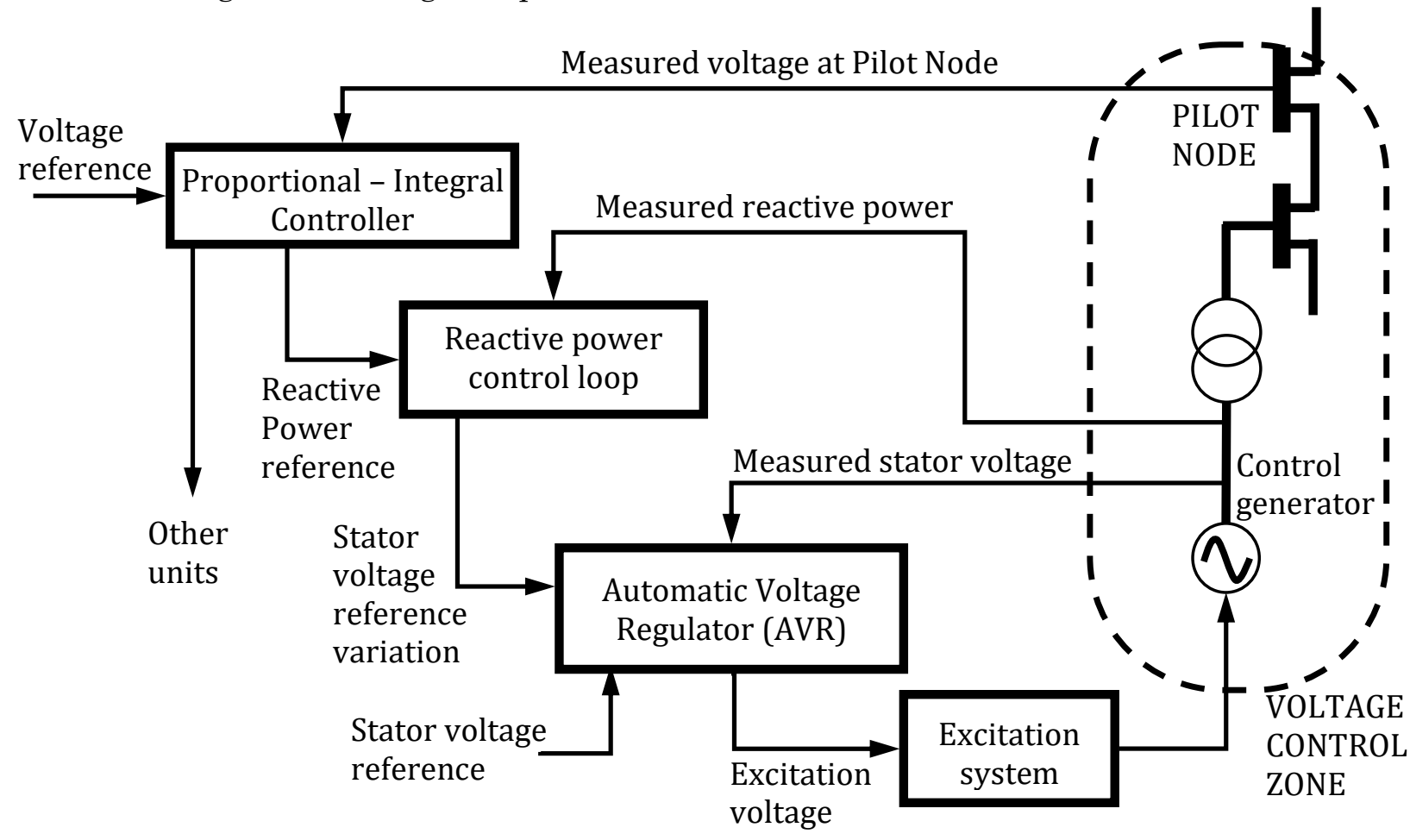

Fig. 2. Conventional SVR approach. Source: Adapted from [6]. 
The restrictions of a power system can be represented in the linearized form [10] shown in (1):

$$
\left[\begin{array}{l}
\Delta P \\
\Delta Q
\end{array}\right]=\left[\begin{array}{ll}
J_{P \theta} & J_{P V} \\
J_{Q \theta} & J_{Q V}
\end{array}\right]\left[\begin{array}{l}
\Delta \theta \\
\Delta V
\end{array}\right]
$$

where $\Delta P, \Delta Q, \Delta \theta, \Delta V$ represent incremental changes in real power, reactive power, voltage angle, and voltage magnitude of system nodes, respectively; and $J_{P \theta}, J_{P V}, J_{Q \theta}, J_{Q V}$ are the Jacobian matrix elements.

If active power is kept constant, i.e. $\Delta P=0$, the expression (2) is obtained from $(1)$,

$$
\Delta Q=J_{R} \Delta V
$$

where $J_{R}$ is known as the reduced Jacobian matrix of the system, which is given by (3),

$$
J_{R}=J_{Q V}-J_{Q \theta} J_{P \theta}^{-1} J_{P V}
$$

Besides, from (2), the relationship between $\Delta V$ and $\Delta Q$, will be (4),

$$
\Delta V=J_{R}^{-1} \Delta Q
$$

where $J_{R}^{-1}$ is the reduced $V Q$ Jacobian, where its $i^{\text {th }}$ diagonal element is known as the $V Q$ sensibility at $i^{\text {th }}$ system node.

The matrix of electrical distances plays an important role in the study of independent voltage control zones [14] and it is defined as (5):

$$
D_{i j}=D_{j i}=-\log \left(\alpha_{i j} \alpha_{j i}\right)
$$

where $\quad \alpha_{i j}=\left(\frac{\partial V_{i}}{\partial Q_{j}}\right) /\left(\frac{\partial V_{j}}{\partial Q_{j}}\right), \quad$ and $\quad \alpha_{j i}=$ $\left(\frac{\partial V_{j}}{\partial Q_{i}}\right) /\left(\frac{\partial V_{i}}{\partial Q_{i}}\right)$, whose terms are obtained from the Jacobian matrix.

Matrix $D_{i j}$ defines the electric coupling level between any pair of nodes in the system. As a result, it is used for establishing voltage control zones and selecting pilot nodes and control generators for each one of them. If a high number of pilot nodes is selected, some voltage control zones with high electric coupling among them could be created. In that situation, a control action in a region could strongly affect the voltage behavior of the neighboring nodes, which could have adverse effects on the application of the secondary regulation strategy. On the other hand, an exceptionally low interaction between control zones, i.e. a small number of control zones, could produce a serious deterioration of the network voltage profile, because some node voltage disturbances will probably be neglected by controllers. Therefore, setting a sensibility threshold that defines the interaction level of control zones and their pilot nodes is a fundamental aspect for the SVR scheme.

\subsection{SVR based on the average voltage of the control zones}

The conventional SVR scheme assumes that pilot nodes characterize the voltage behavior of each control zone. Consequent$\mathrm{ly}$, in this second scheme, the voltage behavior of remaining nodes is practically neglected. This situation could disregard some important voltage variations in specific areas, which can affect the general system voltage profile.

An innovative approach to improve SVR performance has been proposed in this work in order to face these specific aspects. The proposed SVR calculates the average voltage of each control zone and defines an appropriate injection of reactive power for each control generator by changing the voltage reference of the AVR. In the new scheme, a previously established weighted balance between injected reactive powers in all the control generators is maintained as in the conventional SVR.

The proposed SVR defines the voltage control zones by using the sensibility matrix in a way that is comparable to the conventional approach. However, this innovative approach characterizes these zones based on their average voltages, thus 
possibly including all load and generation nodes in each zone. The highest level of HVCS could define the participation percentages of all control generators.

In the proposed approach, the average voltage $V_{A k}$ of the $k^{\text {th }}$ control zone is given by (6):

$$
V_{A k}=\frac{1}{m} \sum_{i \in \Omega} V_{i}
$$

where

$\Omega$ : nodes set of the $k^{\text {th }}$ control zone included in the SVR approach

$m$ : number of nodes of $\Omega$

$V_{i}: i^{\text {th }}$ node voltage of $\Omega$

To integrate this new variable into the SVR scheme, an average voltage reference value $\left(V_{\text {ref } k}\right)$ should be defined for each voltage control zone, whose magnitude could correspond to the solution of an optimization problem provided at tertiary stage of HVCS. As shown in Fig. 3, to limit the interference of these new control actions, a PI controller has been incorporated. Its parameters allow to obtain responses with greater time constants than those provided by the PVR.

The proposed SVR scheme with average voltage in a specific control zone is schematized in Fig. 4. In contrast to conventional SVR (where there is only one control generator and pilot node per voltage

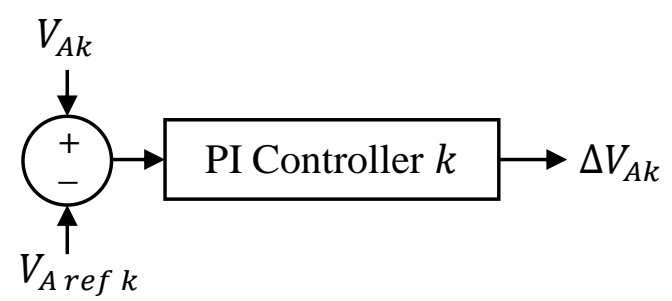

Fig. 3. Average voltage variation in the proposed SVR approach. Source: Authors' own work.

control zone), this approach assumes that there are $\mathrm{n}$ control generators per zone, and the use of the term average voltage finally allows to involve all nodes in the control strategy.

The proposed SVR takes the total reactive power generated at each control zone $\mathrm{Q}_{\mathrm{T}}$, and carries out a specific distribution of its injection into the zone according to the participation factors $\left(\alpha_{1}, \alpha_{2}, \ldots, \alpha_{n}\right)$, which define the percentage of reactive power to be applied by each generator to the area. Even if there is a single control generator in a specific zone (as it usually happens in the conventional SVR), the voltage profile of each area is improved because the average voltage value would be more representative of voltage behavior than the voltage of only one node, as occurs with the use of pilot nodes.

In this new approach, the PVR only accounts AVRs voltage controlling; however, other kinds of continuous reactive power resources could easily be incorporated into this scheme.

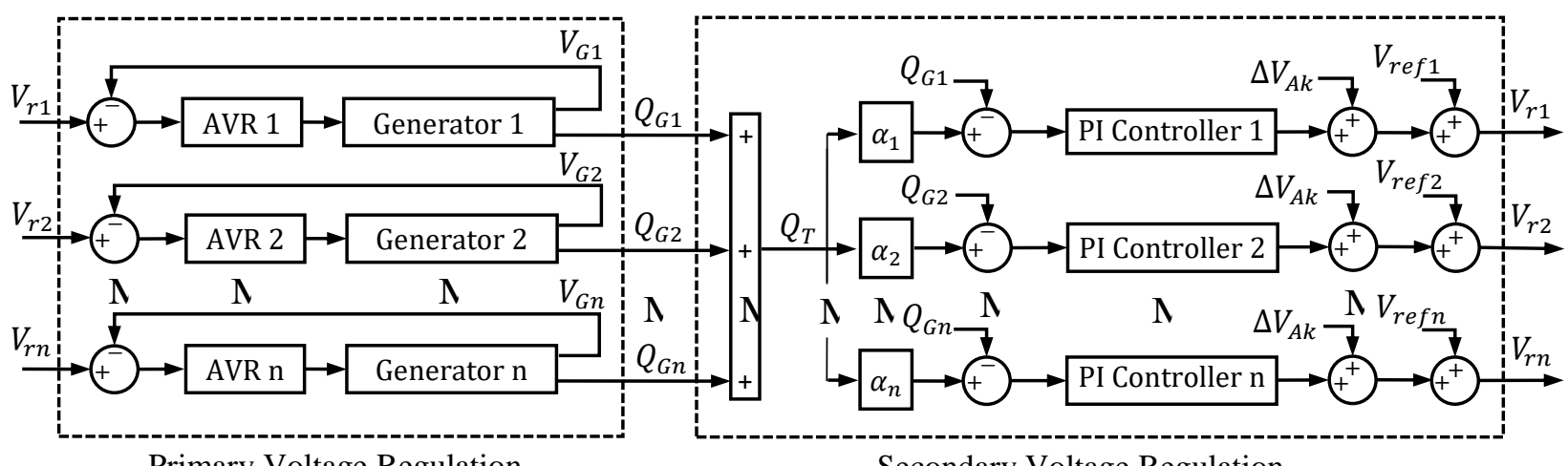

Primary Voltage Regulation

Secondary Voltage Regulation

Fig. 4. Proposed SVR scheme with average voltage control. Source: Authors' own work. 


\section{RESULTS AND DISCUSSION}

In order to evaluate the performance of the proposed SVR scheme, the well-known 14-node IEEE system has been implemented. Its parameters and dynamical model are described in [15]. A conventional SVR was initially applied to this electrical system, followed by the proposed SVR approach based on average voltages. The voltage sensibility matrix of the system was defined to apply both schemes. Pilot nodes, voltage control zones, a specific sensibility threshold, and the short circuit level of all network nodes were selected from this matrix. As a result, Fig. 5 shows the two defined voltage control zones.

The resulting system division is similar to that published in [16], where a different system partitioning method was used. There are some comparable aspects be- tween these two partitions: generators 1,2 , and 3 belong to the same voltage control zone, and nodes 6, 11, 12, and 13 are grouped in another similar zone. The differences between these partitions are mainly due to the electrical distance of the thresholds chosen in each case. As can be noted in Fig. 5, nodes 8 and 14 are initially excluded from any voltage control zone because they exceed the defined electrical distance threshold. The pilot nodes for control zones 1 and 2 correspond to nodes 5 and 13 , respectively.

The three generators located in voltage control zone 1 were included in implemented SVR approaches, i.e. all generators in this area were taken as control generators, while in voltage control zone 2 there is only one control generator, which corresponds to generator 6 . The reactive power participation percentages injected by each

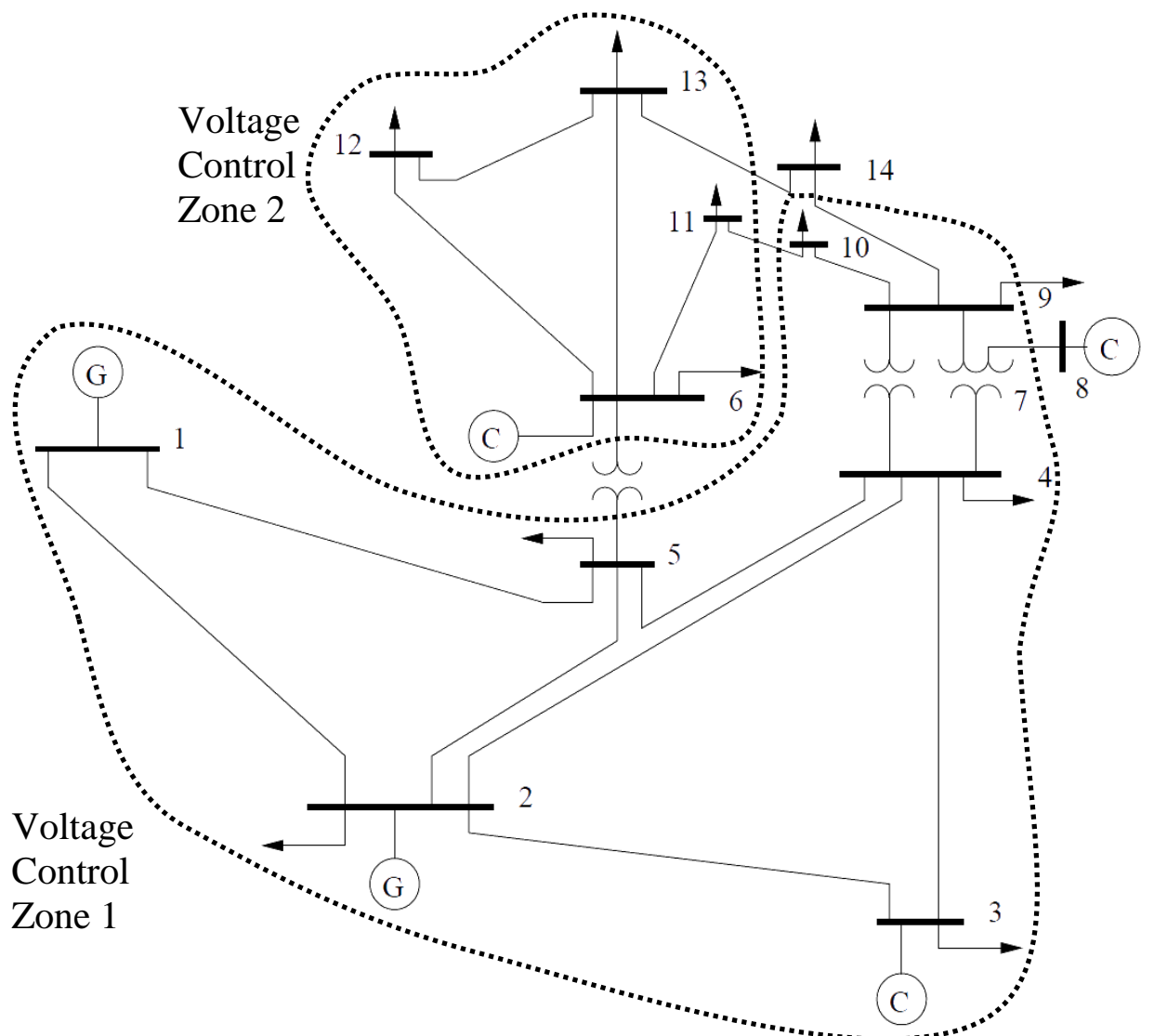

Fig. 5. Defined voltage control zones in 14-node IEEE system. Source: Adapted from [15]. 
control generator in zone 1 were maintained as indicated by the power flow solution in the initial operating point. On the other hand, after analyzing the electrical distances between nodes, it was decided that generator 8 would not participate in any SVR scheme; hence its voltage will only be controlled by its own AVR.

In order to compare the performance of the conventional SVR with the proposed alternative, a topological change was made to the network taking into account electrically remote nodes with respect to the established pilot nodes. For this purpose, system voltage profile, i.e. the average voltage of control zones, was analyzed before and after the outage of the transmission line between nodes 10 and 11 , which is one of the lines connecting the two defined voltage control zones. This abrupt topological change was made exactly 50 seconds into the simulation; hence, before this time, the system exhibits a quasistationary condition. At this point, it should be clarified that, in the proposed SVR, the voltage of node 14 was integrated into the calculation of the average voltage of zone 1 in order to explore the method's flexibility. Nevertheless, as it can be verified, this small variation did not produce significant effects on results.
When network disturbances occur, the reactive power flowing between lines 10 and 11 totally disappears and, consequently, the amount of reactive power delivered to the network by generators has to change. Therefore, as expected, this situation affects all network voltage levels. Figures 6 and 7 particularly show the nodevoltage dynamical responses directly associated with this failure resulting from the two strategies under analysis.

Network average voltages during the first stationary condition were taken as a reference value, i.e. it was assumed that this initial power flow reflected an appropriated operation point and satisfied some constraints defined by the TVR stage. In that sense, it is desirable for any SVR strategy applied to power systems to lead the voltage profile to a similar condition after any contingency, at least until a new optimal power flow is established to give other reference values to the system. However, PVR only compensates specific node voltages in the network. Additionally, conventional SVR acts on a few special load nodes, which are identified as the pilot nodes.

Unfortunately, as Fig. 6 shows, it is possible that some nodes barely benefit from conventional SVR implementation. In this work, after the considered

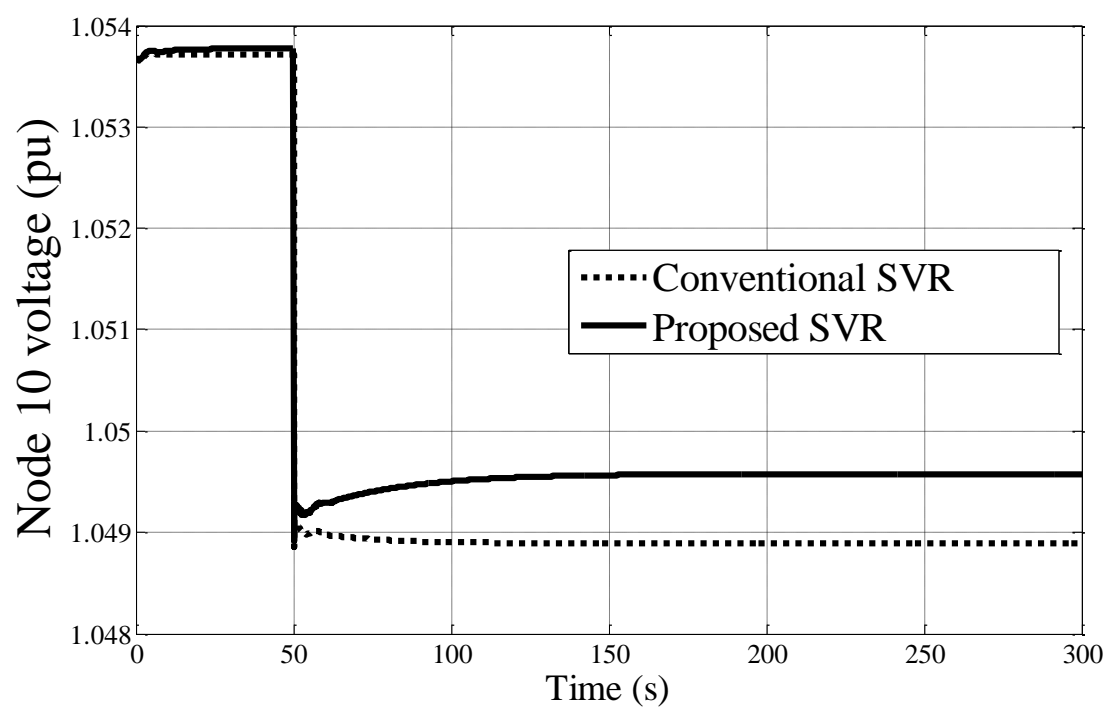

Fig. 6. Node 10's voltage response. Source: Authors' own work. 


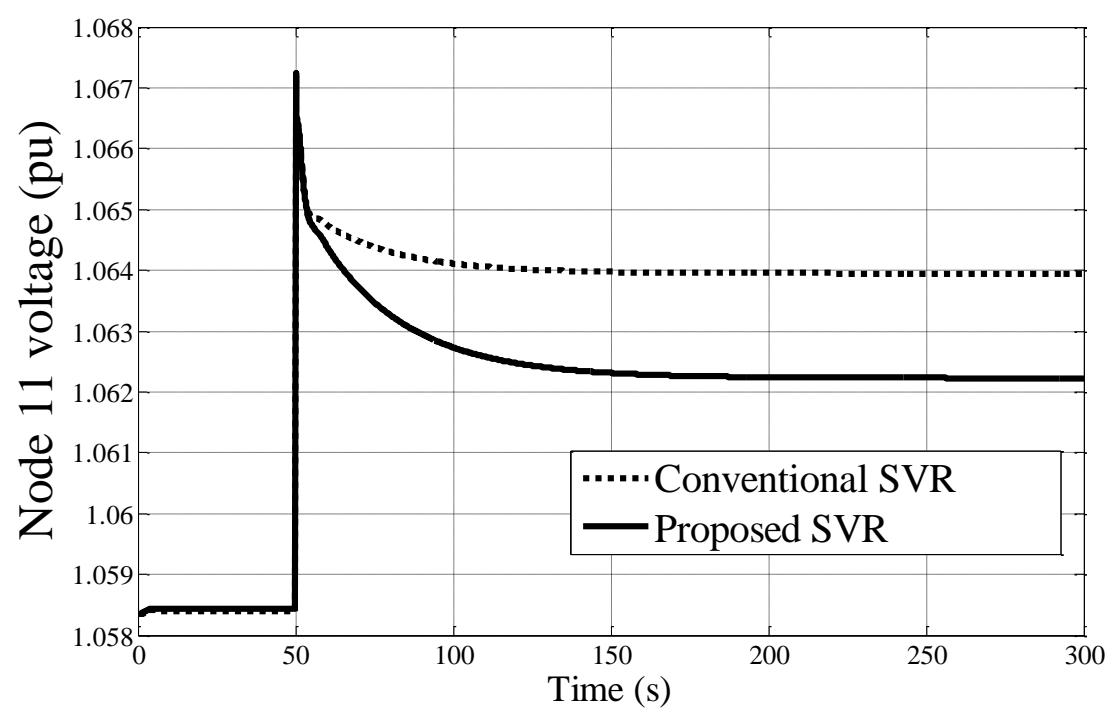

Fig. 7. Node 11's voltage response. Source: Authors' own work.

disturbance, the conventional SVR produces practically no important effect on node 10 's voltage, because only the PVR acts on this variable. On the other hand, the proposed SVR at least tries to recover this voltage to the previous value, because this strategy includes its variation in the average voltage terms in the algorithm.

In a comparable way, the proposed SVR scheme identifies a voltage control problem on node 11 due to the line outage and tries to improve the average voltage of control zone 2 by increasing the reactive power flow, which allows to slightly recover this voltage, as can be seen in Fig. 7. In other words, Figures 6 and 7 allow to visualize some relevant effects of the proposed SVR on communicating nodes between different voltage control zones. These figures reveal the important efforts by this scheme to recover the network voltage profile to a level near where it was before the disturbance.

Figures 8 and 9 show the voltage responses of pilot nodes 5 and 13, respectively, due to a transmission line outage located between nodes 10 and 11 . Some seconds after this disturbance, conventional SVR recovers the voltage magnitudes of the pilot nodes and leads them near the voltage levels prior to the failure. These previous magnitudes were taken as reference values for these specific voltage nodes according to this traditional approach. Conversely, as can be noted in the same plots, the proposed SVR leads these voltages to other levels because this strategy has a different purpose, which requires changing these magnitudes in accordance with the desired voltage profile.

The proposed SVR applies an appropriate reactive power injection in each control zone through the participant control generators in order to reach their corresponding average voltage reference values. Figures 10 and 11 show the average voltages of control zones 1 and 2, respectively, before and after the disconnection of the transmission line. In the first stage of transitory response, just after the disturbance occurred at second 50, PVR's fast action is observed. After this event, the proposed SVR recovers the average voltage in each control zone in about 3 minutes. If that average voltage is accepted as a satisfactory general indicator of network voltage profile, it is quite important to realize how the proposed SVR can recover this 


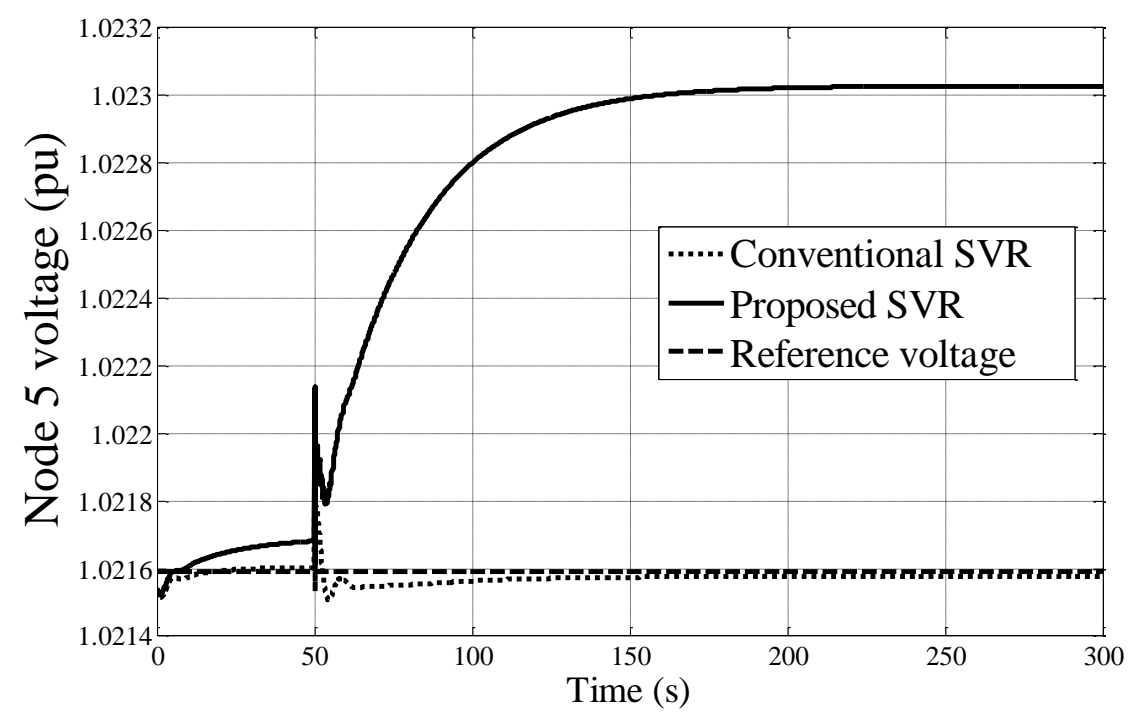

Fig. 8. Node 5's voltage response. Source: Authors' own work.

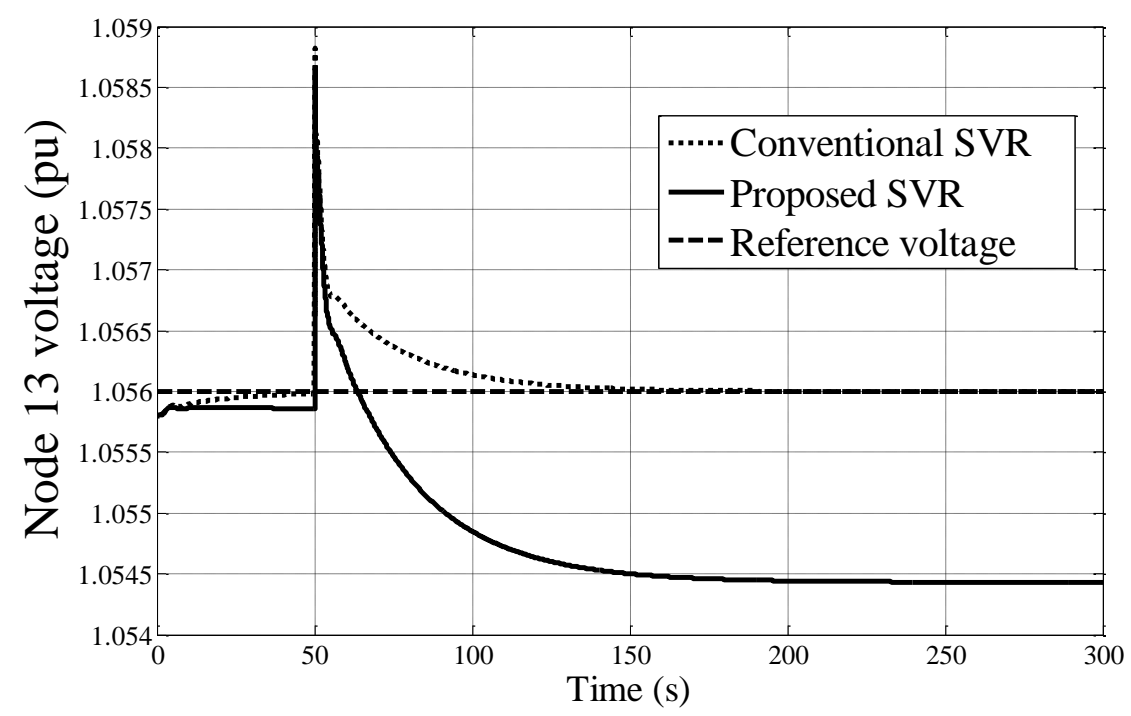

Fig. 9. Node 13's voltage response. Source: Authors' own work.

value in each control zone, while the conventional SVR does not value its significance. In that sense, Fig. 10 allows to visualize how conventional SVR leads the average voltage below the value before the failure, leaving it close to the value given by the PVR stage. This means that on average all node voltages decreased in this zone. Alternatively, Fig. 11 shows how conventional SVR unnecessarily increases the average voltages of all nodes in zone 2 .
On the other hand, Fig. 12 highlights the reactive power responses of all control generators in zone 1 to face the disturbance when the proposed SVR is used. In contrast with the traditional SVR approach, the proposed scheme uses several generators in the control zone. In this particular case, it uses all of them to manipulate the required reactive power and to compensate system voltage levels after the failure. 


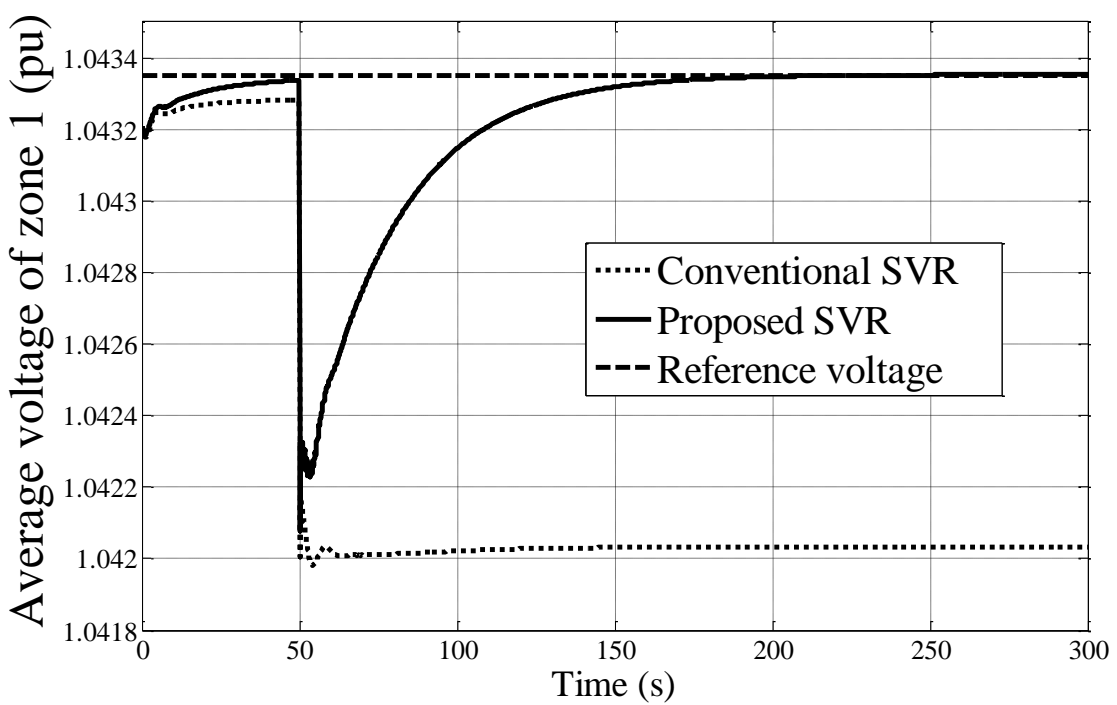

Fig. 10. Response of average voltage in control zone 1. Source: Authors' own work.

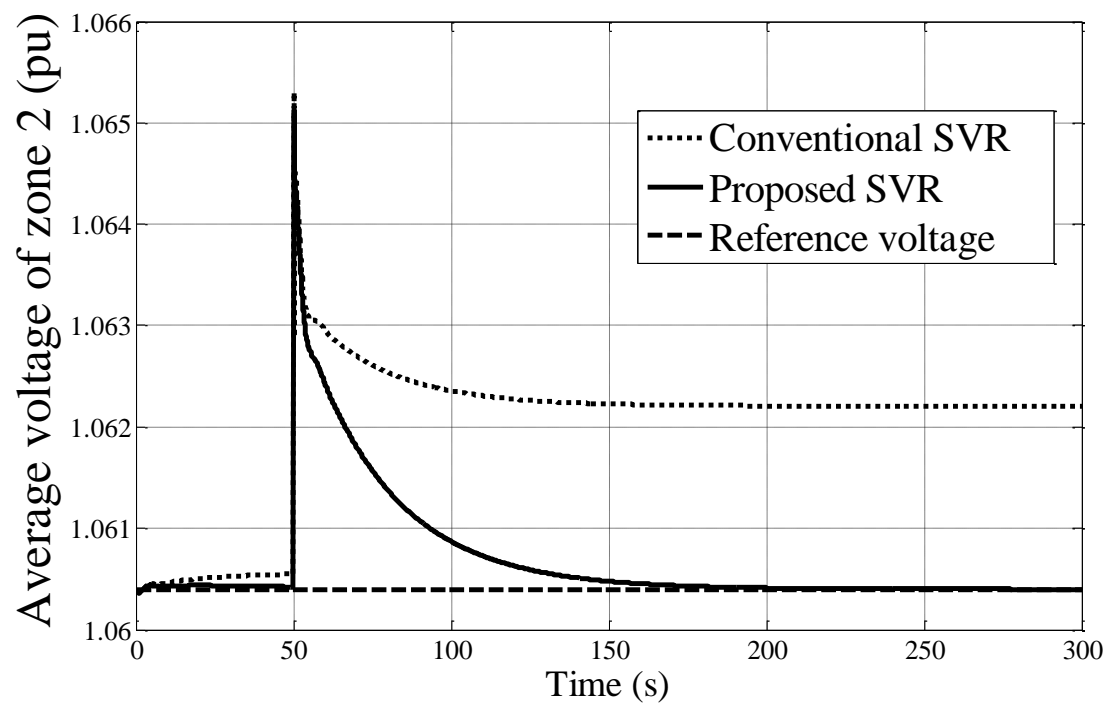

Fig. 11. Response of the average voltage of control zone 2. Source: Authors' own work.

Fig. 12 also reveals how participation factors are applied to distribute reactive power resources of each area in a weighted way, in contrast to what happens in presence of pilot nodes, where a single generator is assigned per area to compensate the voltage level of each one of these specific nodes. For instance, as can be seen in this figure, after the failure, node 2's control generator contributes to more reactive power than the other generators. This is because participation factors were adjusted according to an initial stationary condition, where in fact this generator provides most reactive power. Fig. 13 is congruent with zone 1's voltage behavior shown in Fig. 11. The proposed SVR requires lower reactive power injection from the control generator in control zone 2 than the conventional option. This low injection improves reserves of reactive power to face other possible contingencies in this zone but guarantees an appropriate voltage profile since it takes into account all node voltages by average voltage control. 


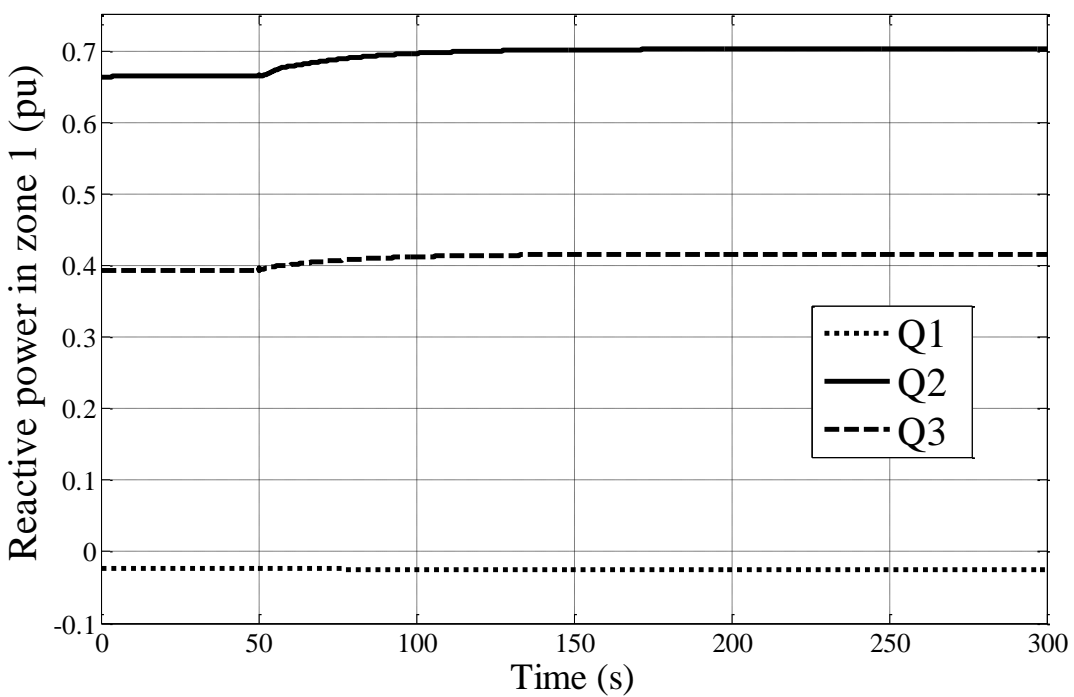

Fig. 12. Reactive power resources of the control zone 1. Source: Authors' own work.

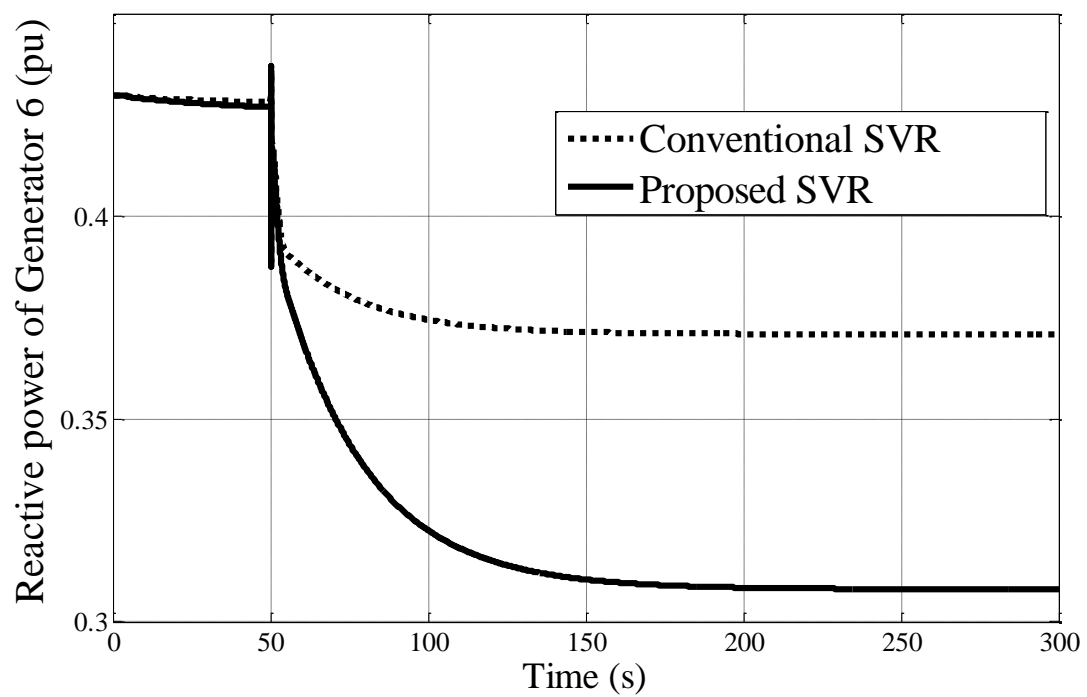

Fig. 13. Reactive power resource of the control zone 2. Source: Authors' own work.

Although many authors have proposed several algorithms for the SVR [10], currently the most-commonly implemented SVR schemes use an approach quite similar to the one presented in this work: conventional SVR with one control generator per voltage control zone. The SVR proposed in this work represents a step ahead for this technique because it could offer more advantages regarding voltage control.
Among these features are its ability to reach different operation points from settings provided by TVR due to the flexibility given by its participation factors, and the possibility of using the voltage measurements of all the nodes in a zone instead of only one, which could reduce measurement errors.

However, as a negative aspect, this approach will require more communication, 
measurement and control equipment, which will increase its implementation costs. As a numerical example comparing additional costs, the conventional SVR applied to the test system only requires two devices to measure and communicate two pilot node voltages to the corresponding regional controllers, but the proposed SVR requires at least 13 of them, because almost all the nodes in the system have to participate in this strategy.

Moreover, this approach should incorporate a specific control algorithm able to adjust the system configuration online and, consequently, reorganize measured and control signals for each established regional regulator. Therefore, it will be necessary to hire more qualified and trained engineers to maintain the system's operation, which in general terms will demand a deep cost/benefit analysis to evaluate the convenience of this strategy in each case.

\section{CONCLUSIONS}

The 14-node IEEE system was divided into two voltage control zones using the electrical distance technique. As a result, a partition like those presented by other researchers (who applied a different algorithm for this task) was obtained.

The proposed SVR led the average voltage of each control zone to its previous values after the disturbance under analysis. This strategy maintained the participation percentages of all control generators according to the reactive power injected by each of them before the failure. This allowed to conveniently distribute the control efforts between these devices.

This approach considers all node voltages in each zone, which improves the recognition of different voltage problems in the network. Furthermore, even disturbances in nodes distant from pilot nodes are detected and control actions are taken to address this phenomenon.

\section{ACKNOWLEDGMENTS}

The authors appreciate the support by Instituto Tecnológico Metropolitano and Universidad Nacional de Colombia in Medellín to carry out this work.

\section{REFERENCES}

[1] V. Venkatasubramanian et al., "Hierarchical Two-Level Voltage Controller for Large Power Systems," IEEE Trans. Power Syst., vol. 31, no. 1, pp. 397-411, Jan. 2016.

[2] V. Alimisis and P. C. Taylor, "Zoning Evaluation for Improved Coordinated Automatic Voltage Control," IEEE Trans. Power Syst., vol. 30, no. 5, pp. 2736-2746, Sep. 2015.

[3] A. Morattab, O. Akhrif, and M. Saad, "Decentralised coordinated secondary voltage control of multi-area power grids using model predictive control," IET Gener. Transm. Distrib., vol. 11, no. 18, pp. 45464555, Dec. 2017.

[4] Q.-Y. Liu, C.-C. Liu, and Q.-F. Liu, "Coordinated Voltage Control With Online Energy Margin Constraints," IEEE Trans. Power Syst., vol. 31, no. 3, pp. 2064-2075, May 2016.

[5] A. Morattab, A. Dalal, O. Akhrif, M. Saad, and S. Lefebvre, "Model Predictive Coordinated secondary voltage control of power grids," in 2012 International Conference on Renewable Energies for Developing Countries (REDEC), 2012, pp. 16.

[6] H. Lefebvre, D. Fragnier, J. Y. Boussion, P. Mallet, and M. Bulot, "Secondary coordinated voltage control system: feedback of EDF," in 2000 Power Engineering Society Summer Meeting (Cat. No.00CH37134), 2000, vol. 1, pp. 290-295.

[7] J. Rios, A. Zamora, M. R. A. Paternina, A. Lopez, and E. Vazquez, "Secondary voltage control areas through energy levels," in 2016 IEEE PES Transmission \& Distribution Conference and Exposition-Latin America (PES T\&D-LA), 2016, pp. 1-6.

[8] H. Vu, P. Pruvot, C. Launay, and Y. Harmand, "An improved voltage control on large-scale power system," IEEE Trans. Power Syst., vol. 11, no. 3, pp. 1295-1303, 1996.

[9] G. Grigoras, B.-C. Neagu, F. Scarlatache, and R. C. Ciobanu, "Identification of pilot nodes for secondary voltage control using K- 
means clustering algorithm," in 2017 IEEE 26th International Symposium on Industrial Electronics (ISIE), 2017, pp. 106-110.

[10] International Council on Large Electric Systems-CIGRE, "Coordinated voltage control in transmission networks," 2007.

[11] N. A. Daher, I. Mougharbel, M. Saad, and H. Y. Kanaan, "Comparative study of partitioning methods used for secondary voltage control in distributed power networks," in 2013 IEEE International Conference on Smart Energy Grid Engineering (SEGE), 2013, pp. 1-7.

[12] Bo $\mathrm{Hu}$, C. A. Canizares, and M. Liu, "Secondary and Tertiary Voltage Regulation based on optimal power flows," in 2010 IREP Symposium Bulk Power System Dynamics and Control - VIII (IREP), 2010, pp. 1-6.

[13] N. Martins, J. C. R. Ferraz, S. Gomes, P. E. M. Quintao, and J. A. Passos, "A demonstration example of secondary voltage regulation: dynamic simulation and continuation power flow results," in 2001 Power Engineering Society Summer Meeting. Conference Proceedings (Cat. No.01CH37262), 2001, pp. 791-796.

[14] P. Lagonotte, J. C. Sabonnadiere, J.-Y. Leost, and J.-P. Paul, "Structural analysis of the electrical system: application to secondary voltage control in France," IEEE Trans. Power Syst., vol. 4, no. 2, pp. 479-486, May 1989.

[15] F. Milano, Power system modelling and scripting, Illustrate. London: Springer Science \& Business Media, 2010.

[16] M. K. Verma and S. C. Srivastava, "Approach to determine voltage control areas considering impact of contingencies," IEE Proc. - Gener. Transm. Distrib., vol. 152, no. 3, pp. 342-350, 2005. 